\title{
Study on the Dissemination Method of the Dongxiang People's Traditional Traits Logo in the New Media Environment
}

\author{
Lei Yang \\ College of Software Engineering, Lanzhou Institute of Technology, \\ Lanzhou, Gansu, 730050, China
}

\begin{abstract}
Dongxiang is a unique ethnic minority in Gansu Province, their faith is Islamic Sunni and its history and folklore are very long. Dongxiang ethnic characteristics pattern which taking folk arts and crafts as the carrier is also with local characteristics and national charm. However, these patterns exist in the majority of handicrafts, daily necessities, historical objects and other objects, it is difficult to preserve and collect; there are the limitations of means to heritage and promote and this series of issues is affecting the spread and application of Dongxiang traditional characteristic pattern in modern society. How to use simple and effective methods, so that more people use the new media technology to intuitive visual means, through the Dongxiang ethnic characteristics pattern to understand the Dongxiang culture has become the urgent problem to be solved.
\end{abstract}

Keywords: Dongxiang; logo; new media

\section{Introduction}

Dongxiang self-proclaimed "Salta" (Sarta) it is the main Sultan, integration of the local Hui, Han, Mongolian, and gradually. The birthplace of the Dongxiang and Silk Road on the important road is known, is the only country to the East as the main ethnic minority Autonomous County. Dongxiang ethnic groups have a profound national culture, a unique national pattern and they are like sleeping in the sea gem waiting for the world's mining. Through these ethnic charm of the pattern study can effectively enhance the awareness of the characteristics of 
ethnic minorities; also from another side to explain and add the Dongxiang ethnic history; In addition, the visual form of the existing pattern data can also be used as Dongxiang ethnic Business card, this kind of national business card is a historical culture and national spirit of the visual summary. In other words, the study of the traditional pattern of Dongxiang is the study of the meaning, history and value of the pattern itself. It is also a new era, new media, the exploration of the relationship between the audience and the communication subject in the new historical background.

With the rapid development of digital media technology and art, the visual elements that carry traditional genes can make their visual effects more vividly and bring people a new visual experience. However, most of these studies are concentrated in the minority pattern itself, and did not extend it to the national pattern of effective communication and dissemination methods level up. Therefore, the following will be the new media environment for the background of the full study of the traditional characteristics of Dongxiang ethnic patterns of communication methods.

\section{The research methods}

The methods of investigation, observation, literature research and data collection are mainly used to study.

Survey and study: through the field study to understand and master the traditional pattern of Dongxiang; by visiting traditional handicraftsmen collect handicrafts, handicrafts in refining the pattern elements; design regional survey questionnaire to help understand the Dongxiang traditional characteristics of the pattern in this It is a kind of scientific and objective reasoning research that lay the foundation for the accuracy of the research.

Observation method: is an intuitive research methods, through the observation of the eye will be investigated to the image, sound and other information, in the field of direct feedback to the brain, to coarse to fine, can effectively improve the investigation efficiency. The method of observation used here is based on the category of graphic semantics, which studies the meaning of different patterns. In order to guide the study of graphic semantics, we can consciously search for the pattern and graphic elements that exist in all aspects of life according to the different meanings represented by the pattern.

Literature research methods: classification of reading the literature, including: text, graphics, symbols, audio, video, etc., these documents exist in a wide range of archives, libraries, libraries and other places, some very difficult to tap the literature, But the study can help us to summarize the law in the research process, find the basis to open up new ideas and discover new problems.

Data collection method: the collection of research data mainly by digital recording means to achieve, the traditional digital recording is mainly recording interviews, digital photo acquisition, video capture and other methods to complete, and now may be three-dimensional imaging and other imaging technology is also applied to strengthen Dimensional pattern collection accuracy, 
comprehensive utilization of advanced digital means can improve the efficiency and record the accuracy.

\section{The access of the traditional pattern with Dongxiang ethnic characteristics}

\subsection{The acquisition of known patterns}

Known pattern finishing is relatively simple. It can summarize the history, the value and present situation of the traditional features of the Dongxiang ethnic group through in-depth investigation and research on the Dongxiang ethnic minority areas and summarize the materials and literatures which have the research significance in the museum and the patterns. And the characteristics of patterns in writing or in-kind classification of refined methods out.

\subsection{The acquisition of unknown patterns}

Dongxiang traditional characteristics of the pattern is difficult to focus on the collection of unknown patterns, these patterns are mostly scattered in the folk, only through the form of private visits to get, collecting more difficult, less accurate, but also involves involving the national habit of collecting Rejected and other practical problems.

\section{Research on the Dongxiang traditional pattern with characteristics}

Dongxiang traditional ethnic pattern with national characteristics is usually in the form of national handicrafts show. These fascinating designs record the cultural spirit and connotation of this nation, including the history and living habits of this nation. Each different pattern has different meanings and spiritual symbols. These designs inherit the simple and precious ancient culture of various ethnic groups, and have a strong local flavour. They are a free and viable form of art, and reflect the local traditional culture, beliefs, legends and customs. In a sense, Dongxiang ethnic characteristics of the traditional pattern of Dongxiang also belong to the characteristics of cultural industries in the visual communication of a deeper level of mining.

\subsection{Pattern innovation}

The creation of folk arts and crafts has a great deal of spontaneity. Most of the folk art creation is the people's amateur activities and the creator has not been a specialized school training, skills and more in a family or individual inheritance, and with self-use, self-entertainment and the nature of self-entertainment [3]. 
Dongxiang traditional pattern of performance basically remain in the simple reproduction and craftsman's emotional expression. We can try to extract some of the most representative of the traditional characteristics of the national pattern, at the same time into the elements of the times and the arts constitute performance methods, maintaining the basic national characteristics, based on these patterns with a sense of the times, the formation of easy to spread Dongxiang ethnic symbols. Dongxiang traditional pattern of innovation is the basis of national handicraft innovation.

\subsection{The handicraft innovation}

Pattern is attached to the buildings, interior furnishings, daily utensils and the existence of decorative arts. In the long-term production practice of the various ethnic groups in the West, decorated with a variety of patterns of life, the formation of a wide range of different patterns, such as the main symbol of Islam is the crescent and the stars that the new moon and the stars that lucky, This particular preference is reflected in the process of creation, there have been a large number of month-shaped pattern [4].

The traditional patterns and innovative patterns in handicrafts to be applied to break through to simple household items, such as: insoles, curtains, clothing, scarves and other items based form, to create and explore the new era of public willing to accept the manual works, Such as: mobile phone chain, mascot, pillow, badge, wedding supplies, souvenirs and so on.

\section{The traditional transmission of Dongxiang ethnic elements}

\subsection{The physical transmission}

It is a kind of graphic culture in the folk spontaneous spread. This spread mainly relies on handicrafts and folk collectors hand-word, with the graphic arts and cultural information of the arts and crafts in the folk artificially preserved. This graphic culture spread more intuitive, but because most are in-kind works, not easy to save.

\subsection{The digital photo transmission}

This method is mainly the existing graphics or lost graphics through digital photos in the form of electronic files saved. Therefore, it is difficult to form a large-scale effective communication and more of the general population is not easy to obtain simple query results. 


\section{The significance of new media technology the spread of Dongxiang ethnic pattern}

With the digital media technology continues to update and development, a variety of digital media terminals have been fully penetrated into all aspects of life, in the age level is unprecedented in the emergence of universal. At present, the traditional media such as $\mathrm{TV}$, radio and newspaper are facing the overall challenge of new media. In some degree, traditional media and new media have already achieved some integration, for example, the TV broadcasted by mobile terminal. If you can effectively use the new media, the traditional features of the Dongxiang family to a new visual display of the visual approach, will win a wider audience.

\section{The communication methods of Dongxiang traditional characteristics pattern in the new media environment}

\subsection{The graphics database platform}

Dongxiang traditional characteristics of the pattern of data sorting and classification rely on a large number of graphics data and information related to the establishment of these data is based on Dongxiang culture, according to the different meaning of the pattern classification. Of course, can also be similar to the classification of graphics retrieval, but the graphics retrieval is now more difficult, complex data information.

This platform is mainly for the image semantic based image retrieval, including the analysis of the needs of users to form on the traditional characteristics of the Dongxiang search database design questions; Second, the collection and processing of image resources, you can use PHOTOSHOP image processing Then, the common semantic properties of these images are extracted, and the index database of the images is built.

\subsection{The static terminal platform}

The traditional characteristics of the Dongxiang family to digital patterns in the form of interactive media to spread, you can also try to carry out arts and crafts network marketing to promote the healthy development of local arts and crafts craftsmen and self-identity. Dongxiang traditional characteristics of the establishment of the database design are the "traditional features Dongxiang family to promote the website to promote the page," the basis for the smooth realization of such a promotion page is built on a static terminal based on, for example, computer web design. 


\subsection{The dynamic terminal platform}

In addition, you can also use the current mainstream HTML5 pages, because the mobile phone-based mobile end does not support Flash, and HTML5 in animation and interaction to meet the basic needs of HTML5 pages as a form of marketing is widely used. To Dongxiang traditional design theme for the design of HTML5 pages, in fact, is a dynamic mobile terminal can operate the web platform, click on the UI icon to enter the next link operation. At present, the mobile phone as the representative of the mobile side has been fully covered to all aspects of life, if you can successfully seize this opportunity, the use of HTML5 operation will be completely shorten the distance of transmission. Of course, this is based on the successful design of UI interface, based on the dynamic interaction to better express national customs, national culture, with a simple operation and style of the interface for faster dissemination, the network more audiences.

\subsection{The virtual experience platform}

It is not difficult to see from the numerous virtual reality studies that this technology is an inclusive platform that can integrate technology and art. It can display the form through time and space in front of the world, and realize the human-machine interaction between audience and virtual platform.

Through mobile digital devices to complete the static image recognition, and thus form dynamic picture-related presentations, this technology mainly by means of UNITY 3D software in the card identification module to complete.

Will be designed with the traditional characteristics of the Dongxiang ethnic patterns of cards through mobile phones and other mobile devices to identify, identify and start playing with the pattern-related ethnic stories, this virtual display method can break the traditional display static pattern of static Limitations, so that static images in a dynamic correlation with the story of the story to help the audience a better sense of immersion, through this method to enhance the sense of participation and further stimulate the sense of identity.

\subsection{The electronics industry platform}

Try to build "Dongxiang national hand-embroidery + digital national pattern" of the industrial chain, which is based on the national culture of ethnic handicrafts industry chain. This chain relies on digital media technology and art, will create a good Dongxiang traditional features printed on the fabric and other fabrics, patterns, embroidery and handicrafts, national culture lovers can be through the scanning pattern to obtain embroidery production process video, the application client can view the embroidery production tutorial on the selected static fabric finish renderings. For example, it is the same as the corresponding identity card number of the picture. Through the industrialization of the promotion can greatly help the Dongxiang ethnic minorities improve their living standards, the formation of a pattern as the background of the cultural industry chain. And 
gradually build the "digital national pattern" characteristics of the cultural industry model.

\section{Acknowledgements}

Gansu Province Philosophy and Social Sciences Planning Project "Research on application and industrialization of piercing embroidery based on digital media in the dissemination of Dongxiang traditional characteristics pattern", project number: YB124

\section{References}

[1] Yang Jingxiu, Hou Ruifang, Hou Weijia, folk embroidery appreciation, Liaoning Fine Arts Publishing House: Shenyang, pp.68-70, 2011

[2] Wang Yufang, Ren Lei, Linxia folk art and the status quo and development, Journal of Lanzhou University of Arts and Science (Social Science Edition), 8 (5), pp.87- 91, 2013

[3] Zhong Jingwen, Introduction to Folklore, Shanghai Literature and Art Publishing House: Shanghai, pp. 18- 20, 2012

[4] Lv Xia. Aesthetic Creation of Folk Art - A Study of the Aesthetic Culture of Minority Nationalities in the West (8), Qinghai Ethnic Studies (Social Science Edition), 9(6), pp.58- 61, 2011

[5] Ni Lebo, Qi Peng. Research and Application of Virtual Demonstration Technology of Unity 3d Products, Digital Technology and Application. 8(4), pp.85-87, 2014 